\title{
عملية جراحية تجعل قصار القامة أطول
}

نور شاهين

عملية جراحية، تسمى إطالة الأطراف أو إطالة عظام الساق، تسمح لقصار القامة أن بصبحوا أطول بحوالي قدم واحد تقريباً (30 سم). مورست تلك العملية بنجاح لمدة حوالي 50 عامًا في مدينة كورغان، في روسيا، وهي من تطوير جراح العظام السوفييتي "غافرييل أ. إليزاروف" عام 1951 بعد أن رأى العديد من محاربي الحرب العالمية الثانية مدن لديهم كسور في الساق لم تلنتئم بعد. ويمكن استخدام تقنية إطالة الأطراف وإعادة تشكيل العظام لاستبدال عظام مفقودة وإطالة أو تقوية أجزاء مشوهة من عظام الأطراف. ويمكن نطبيق هذه التقنية على الأطفال والبالغين على حد سواء، ممن لديهم اختلاف في طول الأطراف منذ الولادة أو بسبب مرض ما أو بسبب إصابات وتشوهات. وتعتمد هذه الطريقة على مبدأ ما يسمى تتشيط تكوين العظام بالسحب أو الثد distraction osteogenesis ويعاكس هذا المفهوم الاعتقاد السائد قديمًا بأنه لا يمكن إعادة توليد العظام. وفي هذه العملية، يمكن لعظم تم قطعه بعطلية جراحية أن يُسحب أو يُمط تدريجيًا، مما يؤدي إلى تكوين عظم جديد في موقع الإطالة (القطع). وهكذا، يمكن تطويل شرائح العظام بنسبة 15 إلى 100 بالمئة من طولها الأصلي. وهناك مجموعة متتوعة من التقنيات المستخدمة، بما في ذلك وسائل نتبيت خارجية أحادية الجانب (من جانب واحد) ودائرية، لتصحيح التشوهات البارزة من العظام angular deformities، بالإضافة إلى تصحيح الاختلاف بين طول الأطراف." ولمعرفة مبدأ هذه التقنية بصرياً، يمكن مشاهدة المرئي (الفيديو) على الرابط أدناه: 2019/06/15 https://youtu.be/ImkuUN2mSdw

المرجح: http://www.theunknownbutnothidden.com/surgery-makes-short-people-foot(تاريخ الدخول taller/ 